\title{
The Selection of a Divisional Reading Room Collection
}

By MARY EDNA ANDERS

$\mathrm{S}^{\mathrm{s}}$ EVERAL TYPES of subject reading rooms have been developed in university libraries where a divisional organization has been adopted. In some libraries, particularly those in new buildings, stacks and reading areas are intermingled and the collection is kept in sequence by its classification. Subject emphasis is achieved by staffing the various service points with librarians specializing in the subject materials shelved in the immediate vicinity. In other libraries titles have been selected from the collection and shelved in areas identified by appropriate subject designations. Factors such as available space, size of the library's collection, and the academic program determine the number of volumes shelved in these reading rooms. Although variations exist, in a closed stack library a subject reading room generally contains from 10,000 to 15,000 titles and seats 150 to 200 people. It normally is staffed by librarians with subject specialization allied to the emphasis of the room. Generally there are three subject divisions: science, social science, and humanities.

In libraries where stack areas are closed, choice of material for the reading room becomes especially significant. The titles included in the divisions or reading rooms constitute the only part of the library used by many students, such as undergraduates without access to the stacks and students who never use the card catalog. Careful selection of the collection, therefore, contributes in considerable degree to the effectiveness of the room as well as to the general library program.

Surprisingly little has been written re-
Dr. Anders is Special Research Scientist, Industrial Development Branch, Engineering Experiment Station, Georgia Institute of Technology.

garding the nature and content of the divisional reading room collections. Descriptions in professional journals, even in handbooks intended for the students of the institution, usually suggest only that "reference books, bibliographies, periodicals, and reserves in each of the fields are located in the various reading rooms." Hall's ${ }^{1}$ twenty tips offer the most help although they are rather general and more concerned with the merits of individual titles than with the reading room collections. Hence, librarians interested in developing a carefully planned selection policy cannot find information in the literature in actual practice in libraries where divisional reading rooms are maintained. Instead they must turn to the general literature on selection and use of material for aid in formulating an acquisition policy, and even here only slight assistance can be found. Although the basic principles of selection apply, additional guides are needed.

Selection of titles for a divisional collection represents the application of criteria to material already in the library collection, or to titles previously judged worth-while additions to the library. Selection of the initial collection is made by simply pulling from the stacks those volumes needed for the reading room. Subsequently, as new titles are purchased,

1 P. C. Hall, “Twenty Tips for Book Selection," Wilson Library Bulletin, XXVII (1953), 652 . 
a decision is made as to whether they will be shelved in the stacks or in the reading rooms. In this way selection for the room is continuous and does not end with the establishment of its collection. To guide this selection and supplement its general book selection policy, the library needs a statement of acquisition policy specifically for the reading rooms.

No adequate expression of such policy for the reading rooms can be formulated until a clear statement of their purpose and function has been prepared. An effective collection cannot be developed without specifying reading room responsibilities. This specification of reading room functions and of a policy regulating development of their collections requires the consideration of a number of factors which may be grouped as follows: those dealing with the library's organization, those relating specifically to the functions of the reading rooms, and those concerning the development of an acquisition policy.

\section{ORganization OF THE LibRaRY}

A library's organization influences the functions assigned to reading rooms. For example, the existence of a general reference room, branch libraries, or professional libraries circumscribes the activities of subject reading rooms. A separate undergraduate library limits their clientele to a more homogeneous group. In addition, reading room activities are affected by circulation procedures; a central circulation desk automatically relieves the reading room staff of those routines. Likewise, the kind of personnel assigned to reading rooms tends to define their functions. Professionally trained specialists offer service which cannot be provided by clerical personnel.

The availability of bibliographical tools including both published works and card catalogs also modifies the programs of the rooms. Administrative decisions regarding organization of services, distribution of personnel, and the nature of bibliographical resources are part of the routine operation of the library. These decisions shape the activities of the specialized reading rooms, and their relationships should be carefully examined because they provide the framework within which the functions of the reading rooms must be specified.

\section{Functions of ReAding Rooms}

In order to define the purpose of divisional reading rooms their basic nature should first be established. Are they specialized reading areas, or are they primarily specialized reference rooms? If a room is to serve primarily a reference collection in social science, for example, the titles will vary from those in a room where the emphasis is placed on reading guidance. More specifically, a complete file of the U.S. Decennial Census Reports will probably be found on the shelves in the former situation but only the more recent volumes in the latter situation.

A second fundamental point that should be considered in outlining the purpose of the rooms is that of the relation of the collections to the program of the institution. Should the reading room collections reflect the literature of their subjects rather than the courses offered by the university? If the collections are geared to the courses offered, one is apt to find a number of gaps; that is, some aspects of a subject completely ignored. On the other hand, if the collections are aimed at a representation of the literature of a subject, one may find that, due to their comprehensiveness, the coverage for specific courses lacks depth. To be more specific, any representative collection in sociology should include publications on gerontology, but not all sociology departments offer courses in that area.

Another question that should be answered before the reading room collections are developed involves consideration of the people whom they serve. 
Conceivably, the users of the room may affect the nature of the collection needed. It can be assumed that graduate and undergraduate students are better served by different types of collections. Although the rooms are expected to serve all library users, it seems expedient to emphasize the needs of one particular category of users in planning the collection.

Possibly these questions are not valid; their answers may have little or no influence on the effectiveness of the collection. Fundamental principles of book selection, however, tend to support the acceptance of their relevance. Due to a lack of evidence to the contrary they are regarded as legitimate questions ultimately affecting the success of divisional reading rooms and the quality of service to their users. Other questions can be raised but probably subordinated to the three above. While additional questions would undoubtedly clarify functions of the rooms, these three provide sufficient foundation to develop an acquisition policy to support the philosophy they express. Actually the important factor is not so much the answer itself but the recognition and the consideration of the questions. Of course the answers should be consistent, firmly based on the best professional thinking and existing knowledge regarding the users' needs.

The following statement of functions of a subject reading room has been formulated to suggest an approach to the development of one in a specific situation.

I The divisional reading room has been organized to bring undergraduate students into direct contact with a large number of books without exposing them to a possibly frustrating experience of attempting to select their titles from the mass of materials available in the stacks. Thus, the collection housed in the room must provide the best choice of those books likely to be of value in terms of undergraduate usage. In planning and operat- ing the room the needs of undergraduates should be emphasized. Their needs are greater because they have fewer privileges than other groups of library users. Their needs likewise exhibit less variation than do those of graduate students and faculty members.

The staff of the room is expected to render reference service and general assistance to users. The room, however, is designed, first of all, to give students direct access to materials. Therefore, this function, rather than reference service, is of paramount importance in planning the room.

The divisional reading room is intended to serve students with a general interest in the subject as well as those enrolled in courses. The collection, consequently, more nearly reflects the literature of a subject than the curriculum of the institution.] While the staff would not in any sense wish to divorce the reading room from the curriculum, it does want to enrich the reading facilities directly available to students by making them something more than reserve or parallel reading collections. Certainly local academic interests and conditions will influence development of the room, but they must not circumscribe it.

Service to the student interested in a minute phase of, or in a specialized approach to, the subject does not fall within the responsibility of the reading room. Such students are expected to use the catalog and to secure additional material from the stacks to meet their needs.

'Because recent books are normally in greater demand than older works, one of the major emphases of the room must be currency of the material. The collection should represent the best of current thinking as well as offer the student some historical perspective on its development.

Essentially, divisional reading rooms 
are conceived as reading areas containing carefully selected titles which enable the undergraduate to read basic materials and to explore in sound general monographs. Each room and its collection will be so organized and administered as to encourage the student to make the fullest use of library facilities and to move beyond class assignments in his intellectual activity.

\section{Acquisition Policy}

Once a clear definition of the functions of the rooms and their relationship to other units of the library exists, an acquisition policy can be formulated. This policy in practice would cover the initial establishment of the reading room collections and subsequent additions to them. As the following paragraphs illustrate, such a policy can be prepared by considering types of material in terms of the functions of the reading rooms.

\section{General guides to selection:}

1. Titles added to the collection shall, in addition to all other factors, be evaluated in terms of appropriateness for undergraduate use. This involves such points as treatment of subject, i. e., highly technical treatment means title is shelved in stacks.

2. Recency of material is of major importance and once a basic collection is established, no title published more than two years previously shall be added to the collection unless it satisfies a very definite and specific need.

3. Generally speaking, no effort is to be made to censor the collection. Material that would be isolated in a restricted section of the stacks, however, shall not be placed on open shelves in the reading room.

4. The collection shall not be developed to serve the special student. Research material shall remain in or be sent to the stacks.
5. The collection shall include titles for the serious reader.

6. Format shall be considered when more than one edition of a title is available, and preference shall be given to attractive and readable editions.

7. Paperbacks shall be used when available to meet the need for multiple copies.

\section{Reference books:}

1. Reference titles used regularly shall be shelved in the room; however, seldom used titles shall not be added to the collection because they reduce the amount of space available for books used by the students.

2. While the latest edition of a reference title is the only one found in the room normally, in the case of continuations such as Annual Register, as many volumes as experience indicates are necessary shall be retained.

\section{Classics:}

1. Germinal and landmark works shall be included freely in the collections.

2. Whenever possible, editions with notes or separately published commentaries about such works shall be included, keeping in mind that they are intended for the use of undergraduates and not for students engaged in graduate research.

Writings of leading figures in the respective subjects:

1. Because of their potential research value complete works of authors and collections of their writings and papers shall be shelved in the stacks rather than in the reading rooms.

2. The reading rooms shall tend to acquire "portable" and selected editions of the writings of the various authors.

3. The reading rooms shall include good editions of the outstanding 
titles rather than the complete works of an author.

\section{Series:}

1. University series in various fields shall not be added to the room collections. If individual titles are needed, efforts to secure duplicate copies shall be made.

\section{Foreign language titles:}

1. The rooms shall tend to prefer good translations if available, leaving originals in the stacks.

2. Titles in languages not taught on the campus shall not normally be added to the room.

3. The foreign language section of the humanities division shall provide material for the language student.

\section{New books:}

1. New books are to be added freely but with the realization that each new title means one already in the room must be retired to the stacks.

\section{Reserve books:}

1. Reserve books shall be shelved in a central reserve collection rather than in the various reading rooms.

\section{Periodicals:}

1. Selected current issues of periodicals shall be kept in the reading room but bound volumes, with the exception of those in science, shall be shelved in the stacks.

The preceding paragraphs indicate the type of problems that arise regularly regarding the nature of the material in the divisional reading room collection. By enumerating the functions of the reading rooms and preparing a written statement of acquisition policy, the library staff will have provided guides that will aid in the daily operation of the rooms and in the periodic evaluations of their effectiveness.

\section{Cyrillic Union Catalog Microprints}

A microprint edition of the Library of Congress Cyrillic Union Catalog is being published. Containing over 708,000 cards arranged by author and added entry, by title, and by subject, the Cyrillic Union Catalog consists of all the entries in Russian, Ukrainian, Byelorussian, Bulgarian, and Serbian reported to the Library of Congress by 185 major research libraries in the United States and Canada up to 1956.

All entries are transliterated into the Roman alphabet. For the benefit of readers not familiar with the original languages, English translations of the titles for all post-1917 dated publications, with the exception of belles lettres, are provided.

The microprints will be issued in bound volumes, labeled and indexed, and contained in a slip case so they can be shelved as books. Price will depend on the number of subscriptions received before December, 1961. If fifty-one or more subscriptions are received, the price will be $\$ 360$; if less than that number, $\$ 410$. Each subscription will include a 12-power hand viewer. Subscription orders or inquiries should be directed to the Library Division, Readex Microprint Corp., 115 University Place, New York 3. 